\title{
SEASONAL VARIATION OF GILL, SKIN, MUSCLE, LIVER AND KIDNEY PATHOLOGY OF MRIGAL (Cirrhinus cirrhosus) IN CULTURAL POND FISHERIES, MYMENSINGH, BANGLADESH
}

\author{
D. R. Das ${ }^{1} *$ and K. J. Chandra ${ }^{2}$ \\ ${ }^{1}$ Bangladesh Fisheries Research Institute, Floodplain Substation, Santaher, Bogra, Bangladesh; ${ }^{2}$ Department of \\ Aquaculture, Bangladesh Agricultural University, Mymensingh
}

\begin{abstract}
An investigation on the seasonal variation of gill, skin muscle, liver and kidney pathology of Mrigal (Cirrhinus cirrhosus) was carried out from four Government (Govt.) and four Private (Pvt.) fish farms, Mymensingh, Bangladesh during June, 2010 to May, 2012. Fish sampling and water quality parameters were monitored monthly basis. For histopathological studies skin, muscle, gill, liver and kidney were collected, processed and stained in Haematoxylin and Eosin. Histologically, Mrigal of different fish farms were more affected in colder months. All the investigated organs of Mrigal were exhibited few abnormalities during summer, however, mild hyperplasia, haemorrhage, partial loss of secondary gill lamellae, marked and hypertrophy was observed during the rainy season. Several pathological changes like necrosis, fungal granuloma, protozoan and monogenean cyst, vacuolation, melanomacrophase, haemorrhage, hypertrophy, hyperplasia and clubbing were recorded in all the investigated organs. Among them fish gills and skin were more affected followed by liver and kidney. In some cases, large bacterial colony and protozoan cyst were observed in the secondary gill lamellae of Mrigal. The ectoparasites were very common in gills and skin of all fishes. Water quality parameters were taken and management practices were investigated fortnightly interval in different farms. These were almost similar for all experimental ponds. The risk of being infestation by parasites of carp significantly $(\mathrm{p}<0.001)$ increased when the water quality parameters such as temperature, dissolved oxygen, $\mathrm{pH}$, ammonia, hardness, alkalinity, transparency and depth of water etc. were not maintained the optimum level.
\end{abstract}

Keywords: Seasonal variation, Cirrhinus cirrhosus, pathological, protozoan and monogenean cyst

\section{INTRODUCTION}

Among inland closed water fisheries in Bangladesh, ponds contribute significantly to overcome malnutrition. Ponds serve as habitat for many large as well as small indigenous fishes in Bangladesh. Mrigal, C. cirrhosus (Hamilton) is one of the important major indigenous fish, found throughout the country. The mrigal is popular due to its adaptability and qualities as a food fish. However, natural populations of the fish are rapidly decreasing due to unregulated harvest, habitat degradation and other human interferences that cause potentially increase the incidence of stress, infection and disease. Disease in fish can reduce production and economic success of aquaculture. The introduction of epizootic ulcerative syndrome (EUS) resulted in Channa spp, Puntius spp, Anabas sp. and other indigenous fish species being seriously affected (Barua et al., 1991). External parasites infection of the skin and gill is a common problem of fish health under aquaculture farming conditions. Parasites damage epidermis and many species of parasites actively fed on underlying tissue and blood. Gill by its nature, provide a good supply of nutrients and relatively safe locations preferred by external protozoa and monogeneantrematode parasites (Roberts, 1978). Funahashi (1980) reported different pathological changes in gill infection of European eel (Anguilla anguilla) and Japanese eel (Anguilla japonicus). In Japanese eel, there was hyperplasia of gill epithelium and advanced cases filament became necrotic and was sloughed off. However, in European eel, clubbing of filament was caused by enlargement of mucous cell. Environmental parameters and seasonal variation might play a significant role in the disease outbreaks of fishes. Ahmed and Hoque (1999) mentioned that cold Environmental with reduced temperature play major role in the incident of disease outbreak in fish in Bangladesh. Epizootic ulcerative syndrome (EUS) outbreak in all countries showed a strong seasonal

*Corresponding e-mail address: drd4272@yahoo.com 


\section{Das and Chandra}

pattern with disease occurrence more common in the months following the major periods of rainfall. Environmental analysis showed that EUS outbreaks were commonly preceded by decreasing alkalinity, hardness and chloride concentration (Phillips, 1994). Histopathology is an important tool, used to diagnose the nature of diseases in animals. It is commonly used diagnostic method for penaeid disease (Bell and Lightner, 1998). However, in Bangladesh, the used of this technique is very limited due to the lack of facilities and technical expertise. Thus, the present study was aimed at investigating the pathology and diseases of gills of a freshwater major carps, Mrigal (C. cirrhosus) from cultural ponds of Mymensingh by using the histological technique.

\section{MATERIALS AND METHODS}

The experimental fish, Mrigal (C. cirrhosus) (Hamilton) were collected from the eight fish farms, 4 Government Farm $\left(\mathrm{P}_{1}\right)$ (Bangladesh Fisheries Research Institute (BFRI), $\left(\mathrm{P}_{2}\right)$ Fish Seed Multiplication Farm (Maskanda), $\left(\mathrm{P}_{3}\right)$ Fish Seed Multiplication Farm (Shambhugonj), $\left(\mathrm{P}_{4}\right)$ Fish Seed Multiplication Farm (Gouripur)) and 4 Private farms (Brahmaputra Fish Farm $\left(\mathrm{P}_{5}\right)$, Deshbondhu Fish Farm $\left(\mathrm{P}_{6}\right)$, Pankouri Fish Farm $\left(\mathrm{P}_{7}\right)$ and Sornolota Fish Farm $\left(\mathrm{P}_{8}\right)$ were situated at Mymensingh, Bangladesh during June, 2010 to May, 2012. Samples of 960 fish were collected by seine net from the ponds at monthly intervals. Live Samples were brought to the fish diseases at Laboratory of the Aquaculture, Department of Aquaculture, Bangladesh Agricultural University, Mymensingh, Bangladesh, in a bucket containing water. The fish were than anaesthetized by blunt trauma to the head. Opercula of fish were removed to collect portion of gill, which were then fixed in $10 \%$ neutral buffered formalin. After 24 hours of fixation, the samples were dehydrated, cleared and infiltrated in an automatic tissue processor using alcoholic series of higher concentration, xylene and paraffin wax. The samples were embedded with molten wax, steel mold and plastic holder, which were labeled previously. Sections were taken by a microtome, placed in water bath $\left(24^{0} \mathrm{C}\right)$ and picked over a labeled glass slide. The Sections were stained with hematoxylin and eosin, mounted with Canada balsam and over slips. The stained slides were examined with microscope. Comparative histopathological studies were recorded and expressed season wise as the summer season (February to May), the rainy season (June to September) and the winter season (October to January). A fortnightly record of temperature, $\mathrm{P}^{\mathrm{H}}$, dissolved oxygen (DO), hardness and ammonia were made and their average values were expressed season wise. The experiment was carried out over a period of 24 months. Chi-square test used to carry out statically analysis (Zar, 1984).

\section{Gill pathology of Mrigal}

In winter months (October to January) both the primary and secondary gill lamellae had marked hypertrophy $(\mathrm{HY})$ and haemorrhage $(\mathrm{H})$. In primary and secondary gill lamellae, pillar cell, inter lamellar region, central axis were totally lost and degenerated (arrow) due to monogenean (MT) and protozoan cysts (PC) infestations in $\mathrm{P}_{1}$ (Figure 1). However, in January and February, haemorrhage $(\mathrm{H})$, hypertrophy (HY), protozoan cyst (PC), monogenean (MT) parasite and necrosis (N) were observed in $\mathrm{P}_{2}$ (Figure 2). The gills of $\mathrm{P}_{3}$ in January also showed almost similar pathologies (Figure 3). The gills of $\mathrm{P}_{4}$ farm fish in December had lamellar missing (arrow) with the presence of monogenean (MT), protozoan cysts (PC), haemorrhage $(\mathrm{H})$, hypertrophy $(\mathrm{HY})$ and hyperplasia (HYP) in gill lamellae (Figure 4). Gill lamellae were splitted (SP), hemorrhaged (H), having monogenetic trematodes (MT) and protozoan cyst (PC)in $\mathrm{P}_{5}($ Figure 5). In December, January and February, hypertrophy (HY), monogenetic trematodes (MT) and protozoan cyst (PC)were found in $\mathrm{P}_{6}($ Figure 6). Almost similar pathological change also observed in $\mathrm{P}_{7}$ (Figure 7). Gill had hypertrophy $(\mathrm{HY})$, haemorrhage $(\mathrm{H})$, vacuums $(\mathrm{V})$, necrosis $(\mathrm{N})$, clubbing $(\mathrm{CB})$ with the presence of monogenetic trematodes $(\mathrm{MT})$ and protozoan cyst (PC) in primary gill lamellae in $\mathrm{P}_{8}$ (Figure 8). In March, primary gill lamellae were also hypertrophied (HY) and hyperplasid (HYP). Several primary gill lamellae were clubbed (CB) with the accumulation of many inflammatory cells especially at the base of the primary gill lamellae. During summer gill lamellae were normal. 
Seasonal variation of gill, skin muscle, liver and kidney pathology of Mrigal
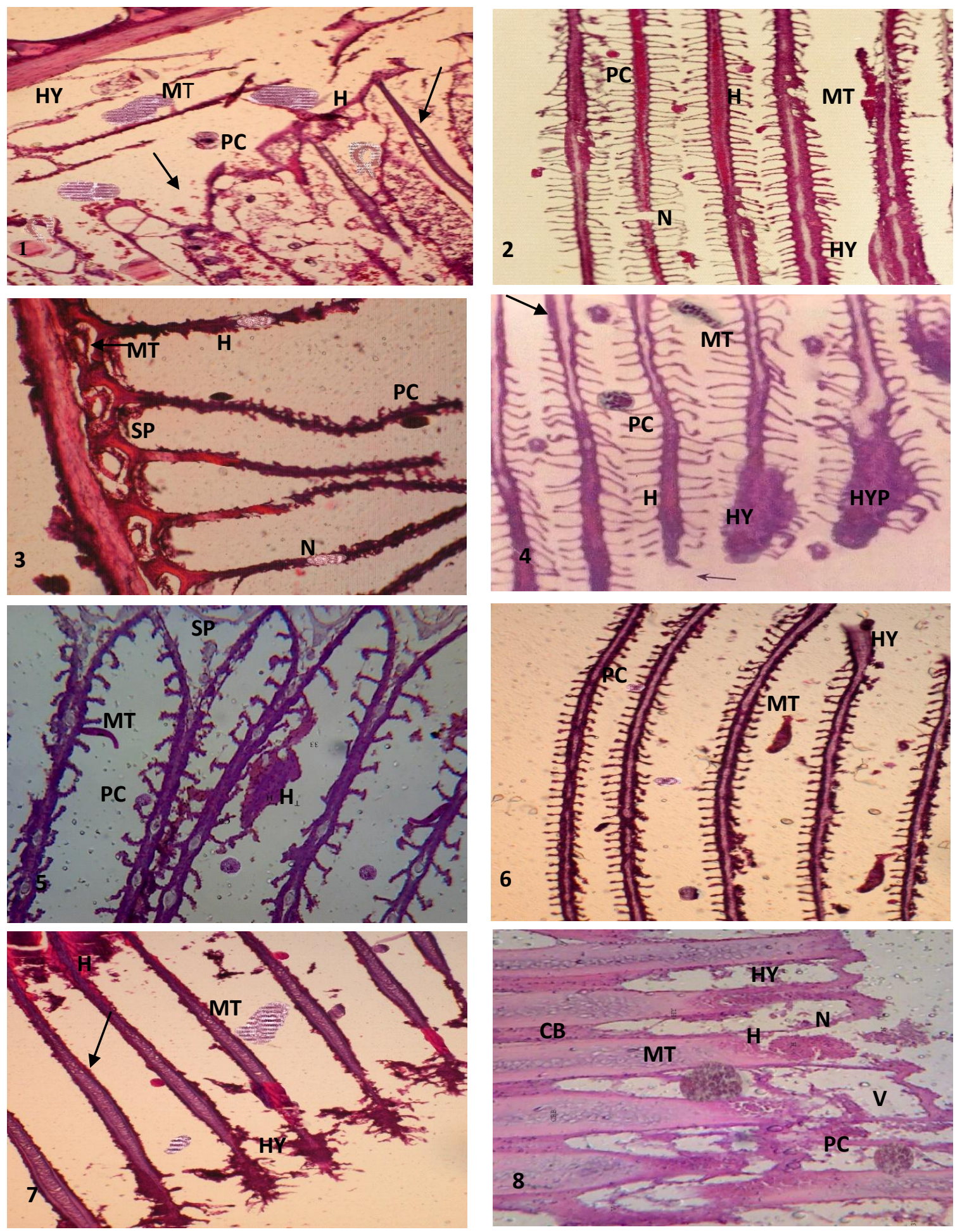


\section{Das and Chandra}

\section{Pathology of skin and muscle of Mrigal}

In August, $\mathrm{P}_{1}$ showed loss of epidermis (arrow), dermis splited (SP) and separated from muscle, monogenean (MT) infestations, vacuums (V) and haemorrhage $(H)$ were found in muscle layer (Figure 9). In September, in $P_{2}$ loss of epidermis and dermis (arrow), necrosis (N), vacuums (V), numerous fungal granuloma (FG), fungal hyphae (FH) and monogenetic trematode (MT) were found in muscle (Figure 10).Epidermis sloughed off (arrow) from dermis, dermis splited (SP) from muscle, myotomes were necrotic (N), protozoan cyst (PC), vacuums (V) and melanomacrophage (MMC) were found in many places in October in $\mathrm{P}_{3}$ (Figure 11). Epidermis totally lost (arrow), dermis splited (SP) and separated from muscle and muscle had melanomacrophage (MMC), Gyrodactylus (G) and protozoan cyst (PC) in October of $\mathrm{P}_{4}$ fish (Figure 12). Skin and muscle of $\mathrm{P}_{5}$ exhibited loss of epidermis (arrow), dermis separated (SP) from muscle, melanomacrophage (MMC), necrosis (N) and vacuums (V) were seen in muscle in November (Figure 13). Similar skin pathology were also observed in $P_{6}$ and $P_{7}$ fish farm, along with Argulus (A) and monogenean (MT) infestations in the muscle during December and January (Figures 14 and 15). Almost similar pathological changes were also found in $\mathrm{P}_{8}$ farm fishes along with Lernaea (L) infestation in February in mrigal (Figure 16). Whereas, in March, muscle structure was almost normal except few parasites. In summer, again structure of skin and muscle were found normal.
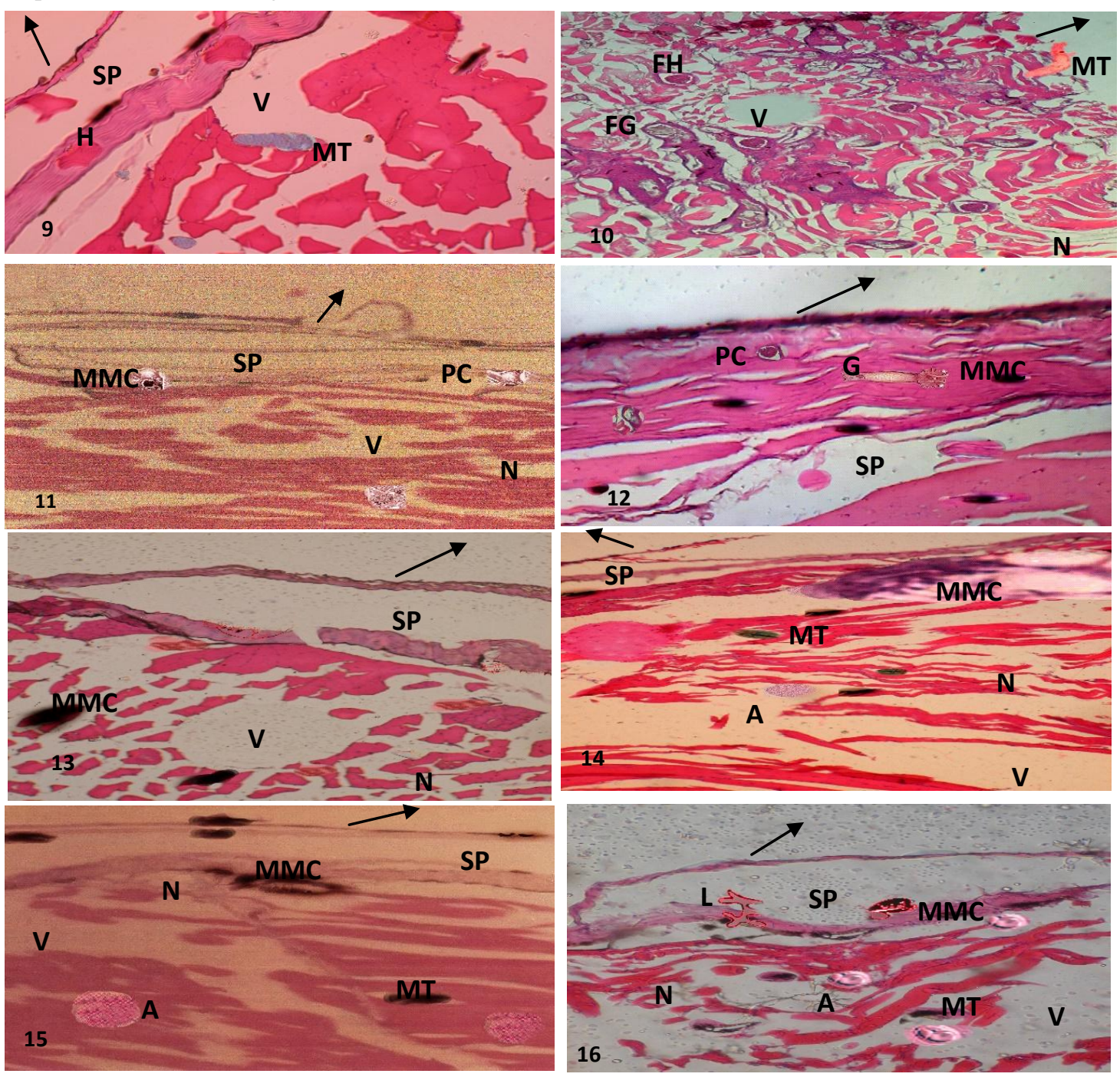


\section{Pathology in liver of Mrigal}

In June and July, hepatocytes of liver were arranged in normal fashion. There were no significant pathological differences in the structure of liver during this period in all farm fishes. Whereas, during the month of August, $\mathrm{P}_{1}$ farm fishes showed vacuums $(\mathrm{V})$, necrosis $(\mathrm{N})$ haemorrhages $(\mathrm{H})$ with Ilets of langerhens (IL) in $\mathrm{P}_{1}$ (Figure 17)and in September, similar pattern pathology also observed with fat droplets (FD) inhepatomaP ${ }_{2}$ farms (Figure 18).Almost similar pathological changes were also found like as protozoan cyst (PC), scattered tissue fragment over the necrotic Ilets (IL), vacuums (V) and hemorrhages $(\mathrm{H})$ were observed in $\mathrm{P}_{3}$ (Figure 19) in October. Whereas, in November, $\mathrm{P}_{4}$ had myxosporean $(\mathrm{M})$ and metacercarial cyst (MC) infection, vacuums $(\mathrm{V})$, hemorrhages $(\mathrm{H})$ and necrosis $(\mathrm{N})$ with extensive destruction of the liver was observed (Figure 20). In December, in $\mathrm{P}_{5}$ farm in Mrigal had vacuums $(\mathrm{V})$, hemorrhages $(\mathrm{H})$, necrosis $(\mathrm{N})$, protozoan cyst $(\mathrm{PC})$ and degenerating cell (DC) were found (Figure 21), whereas, in January, necrotic (N) hepatocytes with vacuums $(\mathrm{V})$ and trichodina $(\mathrm{Tr})$ (Figure 22) in $\mathrm{P}_{6}$, several vacuums $(\mathrm{V})$, hemorrhages $(\mathrm{H})$ and necrosis $(\mathrm{N})$ were noticed (Figure 23) in $\mathrm{P}_{7}$. However, during February and March, hepatocytes and other cells were healing state and hepatocytes and other cells of liver were more or less in normal fashion in April and May. Similar pathology was noticed in Mrigal where few vacuums (V) in hepatocyte was seen but hemorrhages $(\mathrm{H})$ and protozoan cyst (PC) still continued in $\mathrm{P}_{8}$ farm in (Figure 24). But all these pathological changes were almost disappeared in liver of all fishes during February and March.
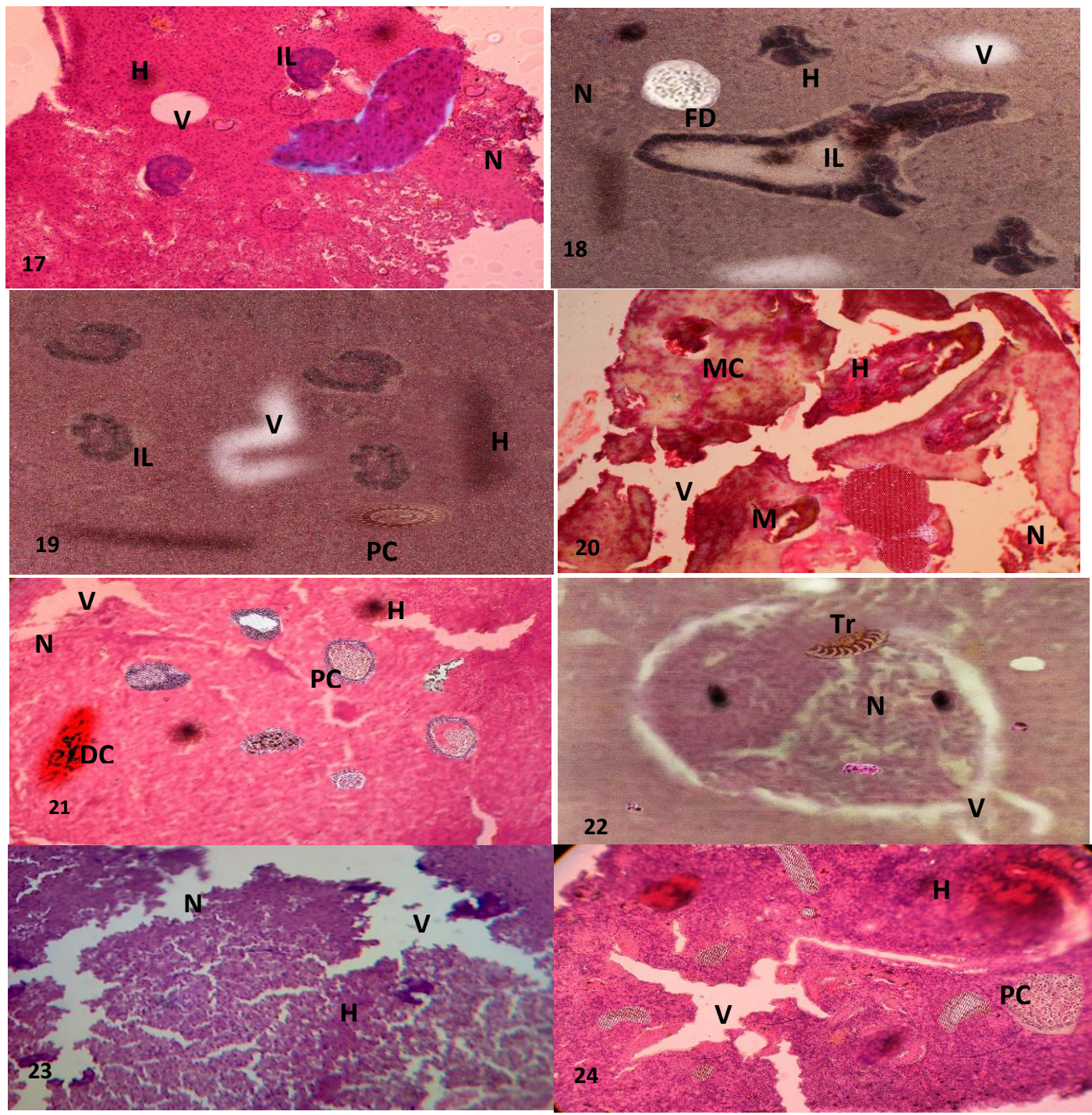


\section{Das and Chandra}

\section{Pathology of kidney in experimental Mrigal fishes}

Kidney structure was normal in the months of June and July in Mrigal in $\mathrm{P}_{1}(25)$ except vacuums (V). In August, Mrigal intensely affected with degenerated glomerulus (DG), vacuum (V), haemorrhage $(\mathrm{H})$ and necrosis $(\mathrm{N})$ were noticed in $\mathrm{P}_{2}$ (Figure 26), However, vacuum $(\mathrm{V})$, haemorrhage $(\mathrm{H})$, pyknosis $(\mathrm{P})$, coagulative necrosis (N) were observed in $\mathrm{P}_{3}$ (Figure 27). In September, vacuums (V) and fat droplets (FD) were found in $\mathrm{P}_{4}$ farm (Figure 28). Coagulative necrosis (N), degenerated kidney tubules (DT), vacuum (V), haemorrhage (H) and renal tubules in a stroma $(\mathrm{S})$ of haemopoietic tissue were observed in $\mathrm{P}_{5}$ (Figure 29) in October. Wide empty spaces were also observed in between kidney tubules. In November, necrosis $(\mathrm{N})$, pyknosis $(\mathrm{P})$ and vacuum $(\mathrm{V})$ was observed in pond $\mathrm{P}_{6}$ (Figure 30). In December, almost same nature of pathology also revealed during this period such as hemorrhage $(\mathrm{H})$, vacuum $(\mathrm{V})$, necrosis $(\mathrm{N})$ and degenerated kidney tubules (DT) and with Bacterial colony $(\mathrm{BC})$ in $\mathrm{P}_{7}$ (Figure 31). In January and February, huge number of pyknotic cells (P) with haemorrhages $(\mathrm{H})$ in $\mathrm{P}_{8}$ farm (Figure 32) and necrotic glomerulus and renal tubules were observed though at healing stage in February and continued it till March. In the month of March, tubule of kidney had hemorrhage $(\mathrm{H})$ and pyknotic cells $(\mathrm{P})$ were also observed in this period. In the months of April and May, tubules of kidney were quite normal in all carp fishes and arranged systematically and no pathological symptoms were detected.
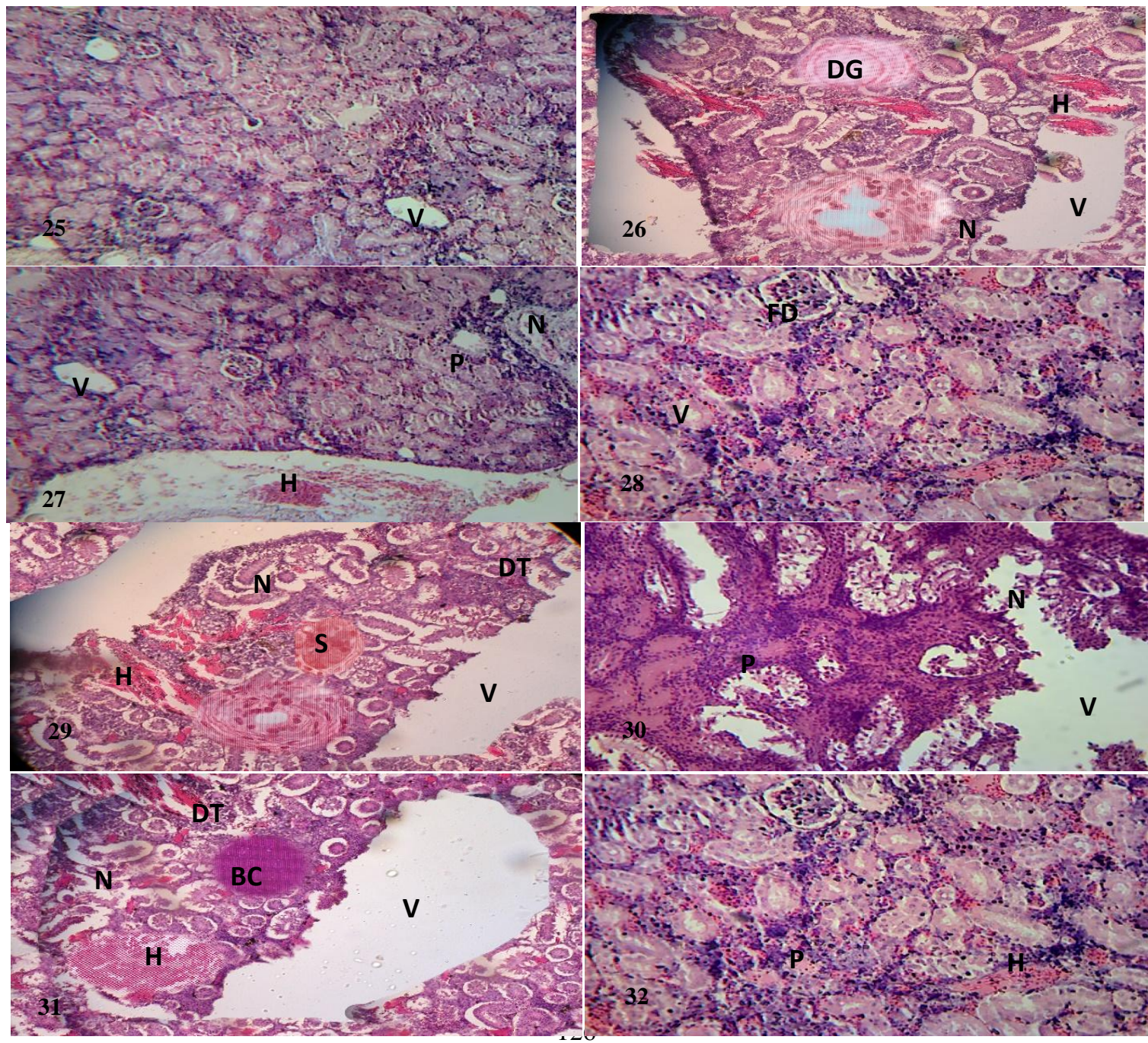


\section{DISCUSSION}

In the present study pathological changes in gills of carps were almost normal in summer season. Whereas, in rainy season, mild necrosis, hypertrophy, hyperplasia, hemorrhage leading to an increased prevalence of parasites in gills of carps were reported. The result are in conformity with the findings of Chandra et al. (2012) who observed that mild hypertrophy and hyperplasia in primary gill lamellae and necrosis in secondary gill lamellae with parasitic infestation in carp in the months of August to October. The associated parasites with pathological signs in fish of present study were also supported by the findings of Akhter et al. (1997). However, marked necrosis, hypertrophy, hyperplasia, hemorrhage, clubbing, loss of lamella and presence of parasites such as monogenetic trematodes and protozoan cysts were attached to the gill lamellae of the fish in all ponds during November to January. Islam et al. (1999) also found monogenetic parasites and protozoan cysts attached to the gill filaments with similar pathology in the gills of juvenile freshwater carp species of Bangladesh from various farming conditions during the period. Such lesions may influence the function of blood circulation in affected gills and if ruptured, the damaged tissue may become portal entrance to secondary infection. However, in the present study the gill pathologies like, loss of primary and secondary gill lamellae, hypertrophy, necrosis, haemorrhages and clubbing were found to be healing stage in the investigating carps from February to March. Recovery of loss of secondary gill lamellae, clubbing, hypertrophy of Indian major carps were reported by Ahmed et al. (1998) during February to March. Parveen et al. (2005) identified almost similar pathological changes in gills of investigated fishes.

Histologically, it was observed that, partial or total loss of epidermis and dermis, dermal splitting, necrosis, pyknosis, vacuolation, hemorrhage and presence of parasites and fungal granuloma observed mainly in skin and muscle pathology from August to January. Almost similar changes were observed in rest of the months with a reduced severity and intensity. Skin and muscle were also severely affected in fishes obtained all ponds towards December and January. The result coincided with the finding of Chandra et al. (2012) who observed that pathologically, skin and muscle were almost normal structure in carps during summer seasons. Whereas, marked pathology such as loss of epidermis and dermal splitting, necrosis and hemorrhage with parasite were seen in rainy season. However, winter samples exhibited severe epidermis and dermis loss, necrosis, pyknosis, vacuolation, hemorrhage in the presence of parasites and fungal granuloma in skin muscle of carp. Hossain et al. (2009) and Moniruzzaman (2000) also found almost similar pathological symptoms in skin and muscle of various freshwater species in Bangladesh. According to Golder et al. (1987) presence of Chilodonella sp., Trichodina sp., Dactylogyrus sp., Ichthyophthirius multifiliis, myxosporean spores and fungal granuloma with necrosis, pyknosis and hemorrhage in muscle of $N$. nandus were significant pathology recorded from ponds. In the present study abrassions in fish in colder months might be due to the presence of various ectoparasites (protozoan, monogenean and crustaceans) which ultimately turned into ulcers. It is well established that the invading ectoparasites cause significant necrotic changes in skin and muscle tissue, produce lession and ultimately result in the formation of dermal ulcers (Ahmed et al., 2007).

Histologically, it was observed that, structure of liver and kidneys were almost normal in summer season (April to July). During rainy season (July to October), mild hepatocytic necrosis, pyknosis and vacuums were found in a few places of liver. Almost similar pathological signs were presence of necrotic kidney tubules, hemorrhage and vacuolation in kidney structure during the period. Akter et al. (2009) observed mild affected liver and kidney with haemorrhages, necrosis and vacuums of A. testudineus during rainy season. Akter et al. (2006) also observed very few vacuoles, hepatic necrosis and disintegration in liver and kidney of $C$. punctatus, $H$. fossilis and $M$. tengara during the same period. An increased pathology was found in the internal organs such as liver and kidney during winter season (November to February). Severe necrosis, hemorrhages, hypertrophy and pyknosis along with the presence of dense protozoan cyst and fungal granuloma were observed in liver and kidney during the period. Hossain et al. (2009) worked on small indigenous species (SIS) from fish markets of Mymensingh and observed that fishes were severely affected during the months of November to January. The authors noticed necrosis, vacuums, haemorrhages, fat droplets, hypertrophy, hyperplasia and pyknotic cells with protozoan cyst and fungal granuloma in liver and kidney of the investigated fish. These findings were almost similar with the works done by Ahmed et al. (2009) and Chinabut et al. (1995). In histological sections of liver and kidney, protozoan cyst was observed along with necrosis, pyknosis, hypertrophy and hemorrhages in the investigated samples. Similar pathological signs of liver and kidney were mentioned by Chandra et al. (2012), Ahmed et al. (2009), Moniruzzaman (2000), Hoque et al. (1999) and Mohan and Sankar (1995) in some 


\section{Das and Chandra}

freshwater culture fishes of Bangladesh. Liu (1981) observed a diffused histozoic myxidian parasite in the caudal kidney of cultured eel in Taiwan. Ahmed et al. (2006) stated that histological tissue section in gill of $B$. gonionotus and kidney positively confirmed massive infection of histozoic myxosporean, Myxobolus sp. Presence of fungal granuloma in the kidney of Catla catla were observed by Hoque et al. (1999). Hatai et al. (1994) recorded fungal parasites in pancreas, liver, kidney, spleen, heart and alimentary canal of fish in Japan. According to Moniruzzaman (2000), liver and kidney of some open water fishes of Bangladesh were necrotic, pyknotic, hypertrophic and had parasites in histological sections. Parveen et al. (2005) found that most of the fishes of Oxbow lakes were severely affected during the month of December and January. Presence of parasites and pathology on the organs, may lead to the occurrence of infection and diseases in fish. Among the investigated organs of the present experiment, gill had an increased pathology and diversified parasites compared to the other organs. This is due to the fact that, gill serves as rich source of nutrients and is in constant contact with the external environment where parasites can easily settle and survive.

\section{CONCLUSION}

Although most of the juvenile of different farms of Mymensingh area were seemed to be healthy, but under histopathological observation it was found that a great percentage of fish were affected by various pathogens especially protozoan parasites. From management point of view, proper attention should be given towards $C$. cirrhosis. Significantly an increased number of fish were affected from June to July and reached its peak in December and January. This might be due to the fact that these two months are the coldest in Bangladesh when water temperature with other parameters goes beyond normal range of tropical fish culture. For this reason organs of all fishes from ponds were more affected during this season. Moreover during culture of C. cirrhosis, more precautionary measures should be taken at the on set of winter season, so that infection in fishes due to pathogens could be controlled in Bangladesh.

\section{ACKNOWLEDGEMENT}

The authors thank the National Agricultural Technology Project (NATP): Phas-1, Project Implementation Unit (PIU) of BARC for financial support for conducting the research work.

\section{REFERENCES}

1. Ahmed GU, Akter MN, Nipa SA and Hossain MM (2009). Investigation on health condition of a freshwater carp, Catla, Rui, andMrigal from Pvt. Farm, Mymensingh, Bangladesh. Journal of the Bangladesh Agrilcultural University 7:419-424.

2. Ahmed GU, Dhar M, Khan MNA and Choi JS (2007). Investigation of diseases of Thai koi, Anabas testudineus (Bloch) from farming conditions in winter. Journal of Life Sciences 17:1309-1314.

3. Ahmed GU, Gosh K, Islam MA and Tazkir-Uz-Zaman AKM (2006). Observation on health status of a juvenile exotic carp Barbodes gonionotus from different farming systems of Bangladesh. Progressive Agriculture 17:185192.

4. Ahmed GU, Haque MM and Hoque MJ (1998). Gill pathology of juvenile carps in nursery ponds. Bangladesh Journal of Fisheries Research 2:63-67.

5. Ahmed GU and Hoque MA (1999). Mycotic involvement in the epizootic ulcerative syndrome of fresh water fishes of Bangladesh: A histopathological study. Asian Fisheries Sciences 12:381-390.

6. Akhter M, De silva J and Khatun A (1997). Helminth parasites of Anabas testudineus (Bloch) in Bangladesh. Journal of Zoology 25:135-138.

7. Akter MN, Ahmed GU and Hossain MS (2009). Seasonal variation of gill pathology of a climbing perch in lake fisheries of Bangladesh. International Journal of Animal and Fisheries Sciences 2:208-213.

8. Akter S, Ahmed GU, Roy MK and Akter N (2006). Investigation of the disease of some small indigenous fish species from Ailee bed, Mymensingh. Progressive Agriculture 17:219-225.

9. BaruaG, Banu ANH and Khan MH (1991). An investigation in to the prevalence of fish disease in Bangladesh during 1988. Bangladesh Journal of Aquaculture 11-13:27-29.

10. Bell TA and Lightner DV (1998). A handbook of normal shrimp histology. Special publication No. I, Baton rouge, L.A.Word Aquaculture Society.

11. Chandra KJ, Basak PK and Das DR (2012). Histopathological observations of farmed carp fingerlings of Mymensingh area. International Research Journal of Applied Life Sciences 1:101-113. 
12. Chinabut S, Roberts RJ, Willoughby LG and Pearson MD (1995).Histopathology of snakehead, Channa striatus (Blooch) experimentally in fected with the specific Aphanomyces fungus associated with epizootic ulcerative syndrome (EUS) at different temperatures. Journal of Fish Diseases 18:41- 47.

13. Funahashi, N (1980). Histopathological changes on gill diseases. Fish Pathology 14:107-115.

14. Golder MI, Chandra KJ and Rahman AKA (1987). Helminth parasitism in Nandus nandus (Hamilton). Bangladesh Journal of Fisheries 10:11-22.

15. Hatai K, Nakamura K, Yuasa K and Wada S (1994). Aphanomyces infection in dwarf gourami (Colisa lalia). Fish Pathology 29:95-99.

16. Hoque MA, Ahmed GU, Rashid H, Sabur MA and Islam MJ (1999). Histopathological study of EUS in an Indian major carp, Catla catla. Bangladesh Journal of Fisheries 22:85-91.

17. Hossain MM, Ahmed GU, Tazri Z and Haque MA (2009). Clinical and pathological investigation of diseases in some small indigenous species (SIS) from fish markets of mymensingh. International Journal of BioResearch 9:7-14.

18. Islam MJ, Ahmed GU, Islam T, Haque MA and Sarkar MGA (1999). Gill pathology of carp's disease from farming systems of Bangladesh. Bangladesh Journal of Fisheries 22:113-118.

19. Liu CI (1981).The pathology of major diseases of eel in Taiwan. Proceedings of the Republic of China-United States Cooperative Science Seminar on Fish Diseases (ed. by Kou GH, Fryer JL, and Landolt ML) National Science Council, Taipei, Taiwan, Republic of China. pp. 34.

20. Mohan CV and Shankar KM (1995). Pathogenic myxosporean infection in the early fry of Indian major carp, Catla catla. Current Sciences 68:548-550.

21. Moniruzzaman M (2000). Investigation on diseases of some small indigenous freshwater fishes of Bangladesh. MS Thesis, Department of Aquaculture, Bangladesh Agricultural University, Mymensingh. 75p.

22. Parveen R, Ahmed GU and Ali ML (2005). Seasonal variation of diseases of some small indigenous fishes from Oxbow lake fisheries of Bangladesh. Pakistan Journal of Zoology 37:53-59.

23. Philips MJ (1994) Relationship between epizootic ulcerative syndrome and the environment.ODA Regional Seminer on Epizootic Ulcerative syndrome at Aquatic Animal Health Research Instictute, Bangkok, Thailand. 2527 January 1994, pp. 109-128.

24. Roberts RJ (1978). Fish Pathology. Balliere Tindall Book, Cassel Ltd., 67-70, pp.144-185.

25. Zar JH (1984). Biostastical Analysis ( $2^{\text {nd }}$ ed). Prentice Hall, New Jersey. P. 718. 